\title{
PENGARUH PENGAWASAN DINAS LLAJ TERHADAP KEDISIPLINAN PENGEMUDI ANGKUTAN UMUM DI KOTA BOGOR
}

\section{THE EFFECT OF SUPERVISION BY DINAS LLAJ TOWARDS DISCIPLINE OF PUBLIC TRANSPORTATION DRIVERS IN BOGOR CITY}

\author{
Muharam Firdaus ${ }^{1}$, Denny Hernawan ${ }^{2}$, Ginung Pratidina ${ }^{3}$ \\ ${ }^{1}$ Jurusan Ilmu Administrasi Negara Fakultas Imu Sosial dan Ilmu Politik Universitas Djuanda, Jl.Tol \\ Ciawi No 1, Kotak Pos 35 Bogor 16770 \\ ${ }^{2}$ Jurusan Ilmu Administrasi Negara Fakultas Imu Sosial dan Ilmu Politik Universitas Djuanda, Jl.Tol \\ Ciawi No 1, Kotak Pos 35 Bogor 16770 \\ ${ }^{3}$ Jurusan Ilmu Administrasi Negara Fakultas Imu Sosial dan Ilmu Politik Universitas Djuanda, Jl.Tol \\ Ciawi No 1, Kotak Pos 35 Bogor 16770
}

(Diterima oleh Dewan Redaksi: 01-08-2015)

(Dipublikasikan oleh Dewan Redaksi: 01-10-2015 )

\begin{abstract}
The purpose of this study is to determine the effect of Discipline Supervision by the Agency (DLLAJ) towards public transportation driver in the city of Bogor, so discipline of public transportation drivers in the city of Bogor can be achieved.

Research method used in this study is associative correlation. The data used are primary and secondary data. Primary data are collected by distributing a questionnaire, and supported by the observations and interviews. Collection of secondary data sourced from documents, literature and related researchs. Research sample are 93 drivers from nine routes of public transportation that crosses main route (Padjajaran Road) and 55 officers of DLLAJ agency Bogor City.

Based on the discussion can be concluded that the effect of supervision taken by Dinas LLAJ towards public transportation in the city of Bogor basically been implemented quite well. Based on the conclusion, the author recommend : DLLAJ officers must provide supervision continuosly, improve traffic infrastructure, especially at the point of congestion and hustle to immediately known root causes. For example, due to lack of traffic signs or in the absence of road markings (zebra crossing) so as to create traffic conditions that are safe, comfortable and smooth.
\end{abstract}

Keywords: Supervision, Discipline, Public Transportation

\begin{abstract}
ABSTRAK
Tujuan dari Penelitian ini untuk mengetahui Pengaruh Pengawasan Dinas LLAJ Terhadap Kedisiplinan Pengemudi Angkutan Umum di Kota Bogor, sehingga dapat mewujudkan kedisiplinan pengemudi angkutan umum dalam berlalu lintas di Kota Bogor. Metoda yang digunakan: asosiatif korelasional. Jenis data yang digunakan adalah data primer dan sekunder . data primer dikumpulkan dengan menyebarkan angket, lalu didukung dengan pengamatan dan wawancara. Pengumpulan data sekunder bersumber dari dokumen, pustaka dan riset terkait. sample penelitian berjumlah 93 orang pengemudi angkutan umum dari sembilan trayek angkutan yang melintasi Jalan Raya Padjajaran dan 55 orang petugas dinas DLLAJ Kota Bogor. Berdasarkan pembahasan dapat disimpulkan bahwa Pengaruh Pengawasan Dinas LLAJ Terhadap Kedisiplinan Pengemudi Angkutan Umum di Kota Bogor pada dasarnya telah dilaksanakan dengan cukup baik. Berdasarkan
\end{abstract}


kesimpulan maka penulis memberikan saran: petugas DLLAJ harus tetap memberikan pengawasan. sarana prasarana lalu lintas terutama pada titik kemacetan dan keramaian agar segera diketahui akar permasalahannya. Misalnya saja karena kurangnya ramburambu lalu lintas atau karena tidak adanya marka jalan (zebra cross) sehingga tercipta kondisi lalu lintas yang aman, nyaman dan lancar.

Kata kunci: Supervisi, Disiplin, Transportasi Publik

Muharam Firdaus , 2016, Pengaruh Pengawasan Dinas LLAJ Terhadap Kedisiplinan Pengemudi Angkutan Umum di Kota Bogor. Jurnal Governansi. 


\section{PENDAHULUAN}

Transportasi darat khususnya bidang lalu lintas dan angkutan jalan merupakan komponen yang sangat penting dari sektor pertumbuhan. Perannya dalam pertumbuhan tidak dapat diabaikan. Perpindahan manusia, barang, atau pun jasa dari satu tempat ke tempat tujuan di seluruh daratan di tanah air memperlihatkan tren kenaikan volume dari tahun ke tahun. Akan tetapi, hal ini tidak didukung oleh tersedianya sarana prasarana lalu lintas dengan lebar dan panjang jalan yang tidak berbanding lurus dengan jumlah kendaraan yang terus meningkat sehingga sering terjadi kemacetan di berbagai tempat atau wilayah. Hal ini bisa dilihat dari menumpuknya kendaraan bermotor pada titik tertentu.

Masalah kemacetan transportasi lalu lintas memang seringkali terjadi di daerah perkotaan yang ada di Indonesia. Hal itu terjadi karena konsentrasi kendaraan banyak menumpuk di area perkotaan, sehingga tidak heran apabila di area perkotaan sering terjadi kemacetan yang disebabkan oleh kepadatan lalu lintas.

Saat ini, kemacetan lalu lintas di perkotaan sudah semakin tidak terkendali. Seiring dengan berjalannya waktu, kondisi kemacetan yang sering terjadi di daerah perkotaan tidak semakin membaik, malah semakin memburuk. Hal ini terjadi karena jumlah kendaraan selalu bertambah dan tidak diimbangi dengan perluasan jalan raya.

Ada beberapa faktor penyebab kemacetan lalu lintas di jalan raya. Faktor yang pertama yaitu karena kondisi jalan yang tidak memenuhi standar kelayakan jalan raya. Banyaknya jalanan yang rusak dan berlubang akan menyebabkan atus lalu lintas menjadi terhambat. Para pengemudi kendaraan bermotor harus mengurangi kecepatannya. Misalnya saja di jalan Raya Padjajaran banyak yang berlubang yang disebabkan oleh curah hujan yang tinggi ataupun karena banyaknya kendaraan besar seperti bus dan truk yang melintas di jalan tersebut. Hal ini tentu akan membuat antrian kendaraan yang panjang dan menyebabkan kemacetan di jalan raya. Faktor yang kedua yaitu karena jumlah kendaraan yang melebihi daya tampung jalan. Pada dasarnya, perbandingan antara jumlah kendaraan dengan daya tampung jalan (VCR) bersanding dengan laju kendaraan yang melintas. Kota Bogor memiliki nilai VCR 0,86 yang artinya kapasitas (jalan rayanya) 10 , terisi 8 (kendaraan) dan rata-rata laju kendaraan yang melintas di kota ini 15,32 kilometer per jam. Banyaknya angkutan umum dan kendaraan pribadi (kendaraan roda dua atau empat) yang melintas di jalan raya pada saat yang bersamaan. Jika kendaraan yang melintas melebihi daya tampung jalan, maka akan menyebabkan kemacetan yang cukup parah. Hal ini biasanya terjadi pada pagi hari ketika orang-orang memulai aktivitas mereka dan pada sore hari ketika orang-orang pulang menuju tempat tinggal mereka. Faktor yang ketiga yaitu karena banyaknya orang yang berlalu lalang untuk menyeberang di tempat yang bukan semestinya. Kurangnya marka jalan (zebra cross) di tempat keramaian seperti disepanjang jalan Raya Padjajaran (terutama di jalan keluar-masuk Mall Botani Square dan Terminal Baranang Siang) dimana banyak orang menyeberang jalan, hal ini akan menyebabkan mereka menyeberang dimana saja dan pada waktu yang tidak menentu. Tidak adanya marka jalan (zebra cross) membuat mereka kurang memperhatikan kondisi sekitar apakah kendaraan melaju dengan cepat atau tidak. Hal ini tentu saja akan membahayakan kedua pihak, baik pengendara kendaraan bermotor maupun pejalan kaki. Untuk mencegah kecelakaan, maka pengendara kendaraan bermotor harus mengurangi kecepatan kendaraannya dan memberikan kesempatan kepada pejalan kaki untuk menyeberang dengan aman. Faktor yang keempat yaitu banyaknya angkutan umum yang mengetem di pusat-pusat keramaian 
untuk mencari penumpang. Para supir angkutan biasanya mengetem kendaraannya di depan Mall Botani Square , Terminal baranang Siang, di jalan Padjajaran, dll. Hal ini akan menyebabkan kemacetan di jalan raya karena posisi angkutan umum yang mengetem akan menghambat arus lalu lintas dan menghalangi kendaraan yang lain untuk melintas. Faktor yang kelima yaitu karena adanya peristiwa kerusuhan atau demonstrasi. Para demonstran turun ke jalanan dengan jumlah yang banyak akan menghalangi para pengendara kendaraan bermotor untuk melintas, sehingga mereka harus menunggu para demonstran untuk menepi dari jalan raya. Seperti yang terjadi pada hari Rabu, 27 April 2016, para pengunjuk rasa/demonstran berunjuk rasa di depan gedung Balaikota. Mereka berasal dari Supir Angkot. Mereka menolak rencana pemerintah kota bahwa Jalur Sistem Satu Arah akan jadi permanen. Demonstrasi ini tentu saja menyebabkan kemacetan, sehingga para pengendara harus menunggu untuk waktu yang cukup lama.

Ketika terjadi kemacetan di jalan raya, hal itu tentu saja akan merugikan banyak pihak. Kemacetan dapat menyebabkan kerugian baik secara materil maupun waktu. Kemacetan di jalan raya akan menghabiskan bahan bakar lebih banyak dibandingkan ketika arus kendaraan lancar. Hal ini tentu saja akan memberatkan para pengendara kendaraan bermotor karena harus mengeluarkan biaya tambahan untuk membeli bahan bakar. Selain kerugian materil, para pengendara kendaraan bermotor juga akan mengalami kerugian pada waktu, para pengendaraan kendaraan pribadi maupun para penumpang angkutan umum akan menghabiskan waktu yang lama di jalan. Sehingga mereka harus terlambat sampai di tempat tujuan.

Setidaknya, ada 8 trayek angkutan kota yang melewati Jalan Raya Pajajaran, yaitu sebagai berikut:
Tabel 1

Jumlah Trayek Angkutan Umum/Kota yang Melintasi Jalan Raya Padjajaran

\begin{tabular}{|c|c|c|}
\hline NO & KENDARAAN/TRAYEK & JUMLAH \\
\hline 1 & 09(Wr. Jambu-Sukasari & 141 \\
\hline 2 & 06(Cihelet-Ramayana) & 157 \\
\hline 3 & $\begin{array}{l}\text { 13(Bt.Kemang- } \\
\text { Ramayana }\end{array}$ & 154 \\
\hline 4 & 03(Br. Siang-Bubulak) & 382 \\
\hline 5 & 01(Br. Siang-Ciawi) & 170 \\
\hline 6 & $\begin{array}{l}\text { 11(Pajajaran Indah- } \\
\text { Ps.Bogor) }\end{array}$ & 53 \\
\hline 7 & 05(Ramyana-Cimahpar) & 162 \\
\hline 8 & $\begin{array}{l}\text { 08(Ramyana- } \\
\text { Indraprasta, Wr. Jambu) }\end{array}$ & 146 \\
\hline \multicolumn{2}{|c|}{ JUMLAH } & 1365 \\
\hline
\end{tabular}

Sumber: Data Dinas LLAJ Kota Bogor (2016)

Dilihat dari banyaknya trayek angkutan kota, maka kemacetan lalu lintas sangat sulit untuk dihindari. Kemacetan ini diperparah karena keadaan sarana dan prasarana yang berada dalam kondisi yang tidak layak, seperti tidak adanya marka jalan (zebra cross) untuk menyeberang jalan. Selain itu, kurangnya rambu-rambu lalu lintas seperti dilarang berhenti atau dilarang parkir membuat kendaraan berhenti/parkir di sembarang tempat. Hal ini harus mendapatkan perhatian yang serius dari pemerintah daerah maupun kota. Setidaknya dibutuhkan kerjasama dari instansi terkait terutama yang berhubungan langsung dengan pengaturan lalu lintas.

Menurut Undang- Undang Nomor 22 Tahun 2009 Pasal 5 ayat 2 dan 3 menyebutkan bahwa urusan pemerintahan di bidang sarana dan prasarana Lalu Lintas dan Angkutan Jalan, oleh kementerian negara yang bertanggung jawab di bidang sarana dan prasarana Lalu Lintas dan Angkatan Jalan (ayat 3 poin b). Sedangkan urusan pemerintahan di bidang registrasi 
dan identifikasi kendaraan bermotor dan pengemudi, penegakan hukum, operasional manajemen dan rekayasa lalu lintas, serta pendidikan berlalu lintas, oleh Kepolisian Republik Indonesia (ayat 3 poin d). Berdasarkan Undang-Undang tersebut, Dinas Lalu Lintas dan Angkutan Jalan (DLLAJ) memiliki tugas dalam kaitannya dengan pengawasan lalu lintas (sarana dan prasarana) di jalan raya dan kepolisian juga memiliki tugas untuk mengatur lalu lintas sehingga Dinas Lalu Lintas dan Angkutan Jalan (DLLAJ) dan Polisi Lalu Lintas memiliki peran yang sangat penting dalam upaya melakukan pengawasan (sarana dan prasarana) dan pengaturan lalu lintas di jalan raya terutama pada ruas jalan yang sering terjadi kemacetan, dalam hal ini yaitu pada ruas jalan Raya Pajajaran.

Menurut Dale (dalam Winardi, 2000:224) dikatakan bahwa pengawasan tidak hanya melihat sesuatu dengan seksama dan melaporkan hasil kegiatan mengawasi, tetapi juga mengandung arti memperbaiki dan meluruskannya sehingga mencapai tujuan yang sesuai dengan apa yang direncanakan. Dari definisi diatas dapat disimpulkan bahwa mengawasi tidak hanya melakukan kegiatan memantau dan melaporkan hasilnya tetapi juga berusaha untuk memperbaiki kondisi di lapangan, apa saja sekiranya yang diperlukan di lapangan guna menciptakan keadaan yang lancar dan kondusif. Sebagai contoh, seperti yang telah dipaparkan diatas, apabila kemacetan disebabkan oleh kurangnya marka jalan (zebra cross) dan ramburambu lalu lintas maka dalam hal ini, pihak DLLAJ dengan segera melaporkan kepada pihak terkait agar segera memasang marka dan rambu-rambu lalu lintas di jalan tersebut. Setelah marka dan rambu-rambu tersebut terpasang, tetap diperlukan pengawasan secara berkala dan konsisten agar tercipta kelancaran dan keamanan dalam berkendara di jalan tersebut.

Menurut Sunarti (2004: 10) "Disiplin adalah kemampuan seseorang untuk bertindak sesuai norma-norma atau aturan-aturan yang berlaku". Dari pengertian diatas dapat disimpulkan bahwa disiplin merupakan tindakan taat pada peraturan dan norma yang dibuat, baik oleh pemerintah maupun oleh masyarakat di suatu daerah. Sikap disiplin sangat perlu untuk ditanamkan oleh setiap individu, karena tujuan dari sikap displin adalah untuk mewujudkan msyarakat yang tertib dan teratur. Jika setiap individu sudah menerapkan sikap disiplin, maka suatu daerah bahkan suatu negara akan menjadi nyaman, aman, tertib, dan teratur. Namun, pada kenyataannya, masih banyak kendala yang dihadapi oleh pemerintah demi mewujudkan negara Indonesia yang disiplin. Salah satu contoh ketidakdisiplinan yang masih sangat sering terjadi yaitu sikap pengemudi yang tidak mengindahkan peraturan-peraturan dalam berlalu lintas.

Bentuk ketidaksiplinan para pengemudi di Jalan raya Pajajaran bemacam-macam.Pertama, banyaknya pengemudi angkutan umum yang mengetem di ruas Jalan Mall Botani Square, kedua jalan ini merupakan jalan yang sering dilewati oleh masyarakat Kota Bogor setelah berbelanja di Mall Botani Square. Ketiga, banyaknya kendaraan yang parkir di ruas jalan Raya Padjajaran Khususnya di depan Masjid Raya Bogor Keempat, banyaknya pengemudi angkutan umum yang menurunkan atau menaikkan penumpangnya di tengah jalan sehingga menimbulkan arus kendaraan yang tidak lancar.

Tindakan ketidaksiplinan yang telah dipaparkan diatas akan sangat mengganggu ketertiban dan kelancaran dalam berlalu lintas, terlebih lagi jika tidak ada upaya yang maksimal untuk mengatasi masalah tersebut. Banyak cara yang dapat dilakukan oleh pemerintah untuk mengatasi masalah tersebut. Salah satunya adalah dengan melakukan pengawasan sarana dan prasarana lalu lintas. Kelengkapan sarana dan prasarana seperti marka jalan (zebra cross) dan 
rambu-rambu lalu lintas (tanda dilarang berhenti, dilarang parkir, dilarang memutar arah, dll) akan sangat menunjang para pengemudi agar disiplin dalam berlalu lintas.

Jika dilihat dari pentingnya pengawasan sarana dan prasarana untuk mewujudkan ketertiban dalam berlalu lintas, maka penulis tertarik untuk membahas permasalahan tersebut dalam skripsi yang berjudul "Pengaruh Pengawasan Dinas LLAJ Terhadapa Kedisiplinan Pengemudi Angkutan Umum di Kota Bogor".

\section{MATERI DAN METODE}

Guna mewujudkan lalu lintas yang aman, nyaman, tertib dan teratur sangatlah penting untuk melaksanakan pengawasan yang dilakukan oleh pihak DLLAJ (Dinas Lalu Lintas dan Angkutan Jalan) karena hal tersebut bertujuan untuk mewujudkan kedisiplinan dalam berlalu lintas di jalan raya. Untuk mengetahui penelitian ini, terlebih dahulu harus mengerti dan memahami arti "pengawasan". Berbagai definisi atau pembatasan tentang "pengawasan" yang telah banyak dikenal.

$\begin{array}{lcr}\text { Menurut } & \text { pendapat } & \text { Manulang ( } \\ \text { 2009) teori George } \mathrm{R} \text { Terry, } \\ \text { pengawasan } & \text { adalah } & \text { proses }\end{array}$
penentuan apa yang harus dicapai yaitu standar, apa yang sedang dilakukan, yaitu menilai pelaksanaan dan bila perlu melakukan perbaikanperbaikan sehingga pelaksanaan sesuai dengan rencana yaitu selaras dengan standar. Selain pengawasan terhadap lalu lintas perlu diadakannya pembinaan displin terhadap pengemudi angkutan umum atau angkutan kota yang mana saat ini banyak pengemudi yang tidak mengerti atau paham terhadap peraturan lalu lintas serta fasilitas rambu-rambu lalu lintas yang ada.
Demikan pula menurut T.Hani Handoko ( 2012 ) teori Newman mengatakan bahwa, "Pengawasan manajemen adalah suatu usaha sistematik untuk menetapkan standar pelaksanaan dengan tujuan tujuan perencanaan, merancangkan informasi umpan balik, membandingkan kegiatan nyata dengan standar yang telah ditetapkan sebelumnya, menentukan dan mengukur."

Menurut T.Hani Handoko

( 2012:10) bahwa tahapan-tahapan dalam proses pengawasan terdiri dari berbagai tahapan sebagaui berikut :
a. Penetapan standar pelaksanaan
b. Penentuan Pengukuran pelaksanaan Kegiatan
c. Pengukuran Pelaksanaan Kegiatan
d. Pembanding pelaksanaan dengan standar dan Analisa penyimpangan.

Menurut H. Malayu Hasibuan (2007:194) ada beberapa indikator yang mempengaruhi tingkat kedisiplinan kerja, diantaranya:

1. Tujuan dan kemampuan

2. Teladan pimpinan

3. Balas Jasa

4. Keadilan

5. Pengawasan melekat

6. Sanksi hukuman

7. Ketegasan

Metode Penelitian yang digunakan dalam penelitian ini adalah metode penelitian asosiatif korelasional

\section{Populasi dan sampel}

Yang dimaksud dengan Populasi adalah wilayah generelisasi yang terdiri atas obyek/subyek yang mempunyai kualitas dan karakteristik tertentu yang ditetapkan oleh peneliti untuk dipelajari dan kemudian ditarik kesimpulannya. ( Sugiono 2007 : 90)

Menurut Sugiyono ( 2009:11) Sampel adalah bagian dari jumlah dan karakteristik 
yang dimiliki oleh populasi tersebut. Bila populasi besar, dan peneliti tidak mungkin mempelajari semua yang ada populasi, misal karena keterbatasan dana, tenaga, waktu, maka peneliti dapat menggunakan sampel yang diambil dari populasi itu. Sampel penelitian ini adalah:

1. Sebagian sopir angkutan kota (umum) yang berjumlah 93 kendaraan.

2. Pegawai Dinas LLAJ Kota Bogor petugas pengawasan sebanyak 55 orang

Untuk menentukan jumlah sampel digunakan rumus Yamane (Sukandarrumidi, 2012 : 56) Berdasarkan rumus Yamane jika populasi 1365, maka didapat sampel 93 pengemudi, untuk Populasi pegawai Dinas LLAJ Khususnya petugas pengawasan digunakan teknik penarikan dengan Table Isaac dan Michael (Sugiyono, 2009: 86-87) dari jumlah populasi 65 orang dengan tingkat kesalahan $10 \%$ didapat sampel 55 orang dengan pengambilan sampelnya dilakukan secara acak (Simple Random Sampling).

\section{TEKNIK ANALISIS DATA}

Analisa data adalah proses mencari dan menyusun secara sistematis data yang diperoleh dari hasil wawancara, catatan dari lapangan dan dokumentasi dengan cara mengorganisasikan data ke dalam kategori, menjabarkan ke dalam unit-unit, menyusun ke dalam pola, memilih mana yang penting dan yang akan dikaji dan dipelajari, serta membuat kesimpulan sehingga mudah dipahami oleh diri sendiri maupun orang lain. Proses analisis data ini dilakukan sejak sebelum memasuki lapangan (locus), dan kemudian analisis data terfokus selama proses dilapangan, data yang diperoleh kemudian akan di analisis sehingga dapat diperoleh suatu kesimpulan dari keseluruh data. Teknik analisa data dalam penelitian ini menggunakan perhitungan Weight Means Score (WMS) yaitu untuk setiap item pertanyaan. Adapun rumus WMS adalah sebagai berikut:

$$
M=\frac{\sum f x}{n}
$$

Keterangan : $\mathrm{M}=$ Angka Penafsiran $\mathrm{x}$

$=\quad$ Pembobolan (skala nilai)

$\mathrm{F}=$ Frekuensi

$=\quad$ Jumlah Sampel

untuk mengetahui kriteria

penafsiran dilakukan dengan cara menghitung interval nilai, yaitu sebagai berikut:

Tabel.2

Kriteria penilaian terhadap angka penafsiran

\begin{tabular}{ccl}
\hline No. & $\begin{array}{c}\text { Angka } \\
\text { Penafsiran }\end{array}$ & Kriteria Penilaian \\
\hline 1. & $4,20-5,00$ & Sangat Baik Sekali \\
2. & $3,41-4,20$ & Baik \\
3. & $2,61-3,40$ & Cukup \\
4. & $1,81-2,60$ & Tidak Baik \\
5. & $1,00-1,80$ & Sangat Tidak Baik \\
\hline
\end{tabular}

Sumber: Metode Penelitian Administrasi. Sugiyono 2012

Selanjutnya pedoman yang digunakan untuk menginterprestasikan nilai Koefisien Korelasi yang didapat, maka penulis menggunakan kriteria berdasarkan pendapat dari Sugiyono (2012), yaitu sebagai berikut:

Tabel .3

Pedoman untuk memberikan Interpretasi Koefisien Korelasi

\begin{tabular}{cc}
\hline INTERVAL & TINGKAT \\
KOEFISIEN & HUBUNGAN \\
\hline $0,00-0,199$ & Sangat Rendah \\
$0,20-0,399$ & Rendah \\
$0,40-0,599$ & Sedang \\
$0,60-0,799$ & Kuat \\
$0,80-1,000$ & Sangat Kuat \\
\hline
\end{tabular}

Untuk menguji signifikasi pengaruh, yaitu apakah pengaruh yang ditemukan itu berlaku untuk seluruh populasi, maka perlu di uji signifikasinya. 


\section{HASIL DAN PEMBAHASAN}

Pengaruh Pengawasan Dinas LLAJ Terhadap Kedisiplinan Pengemudi Angkutan Umum dalam hal ini merupakan tugas yang dilakukan oleh petugas DLLAJ khususnya petugas lalu lintas dalam mengatur lalu lintas serta beberapa tugas lainnya yang berhubungan dengan tata cara penyelenggaraan tata tertib lalu lintas, pengawasan dapat dilihat dari baik atau tidaknya para petugas DLLAJ Kota Bogor dalam melaksanakan tugas -tugasnya dengan baik.

Untuk mengetahui pengawasan lalu lintas DLLAJ diukur berdasarkan variabel pengawasan dari Hani Handoko ( 2012 :10 ) yaitu

1. Penetapan standar pelaksanaan

2. Penentuan pengukuran pelaksanaan kegiatan

3. Pengukuran pelaksanaan kegiatan

4. Pembanding pelaksanaan standar dan analisa penyimpangan

5. Pengambilan tindakan koreksi dila diperlukan

Tabel. 4

Rekapitulasi untuk variabel Pengaruh Pengawasan Dinas LLLAJ Terhadap Kedisiplinan Pengemudi Angkutan Umum di Kota Bogor

\begin{tabular}{clc}
\hline No & \multicolumn{1}{c}{ Dimensi } & $\begin{array}{c}\text { Rata-rata } \\
\text { skor }\end{array}$ \\
\hline 1. & $\begin{array}{l}\text { Penetapan standar } \\
\text { pelaksanaan }\end{array}$ & $\mathbf{3 , 3 9}$ \\
2. & $\begin{array}{l}\text { Penentuan pengukuran } \\
\text { pelaksanaan kegiatan }\end{array}$ & $\mathbf{2 , 9 1}$ \\
3. & $\begin{array}{l}\text { Pengukuran pelaksanaan } \\
\text { kegiatan }\end{array}$ & $\mathbf{3 , 1 9}$ \\
4. & $\begin{array}{l}\text { Pembanding } \\
\text { pelaksanaan dengan } \\
\text { standar dan analisa } \\
\text { penyimpangan }\end{array}$ & $\mathbf{2 , 9 2}$ \\
Pengawasan & Untuk \\
& $\begin{array}{l}\text { Dimensi Pengambilan } \\
\text { Tindakan Koreksi bila } \\
\text { diperlukan } \\
\text { Rata-rata skor }\end{array}$ \\
\hline
\end{tabular}

Berdasarkan tabel di atas diketahui rata-rata skor untuk variabel pengawasan sarana prasarana lalu lintas adalah sebesar 3,06 dengan interpretasi Cukup. Artinya, penilaian responden tentang dimensi penetapan standar pelaksanaan, penentuan pengukuran pelaksanaan kegiatan, pengukuran pelaksanaan kegiatan serta pembanding pelaksanaan dengan standar dan analisa penyimpangan secara garis besar adalah cukup. Hal ini tersebut menunjukan pengawasan pelanggaran lalu lintas oleh DLLAJ sudah cukup, artinya secara kualitas Pengaruh pengawasan DLLAJ Terhadap Kedisiplinan Pengemudi Anokutan IImum di Knta Rnoor sudah Sumber: Metode Penelitian Administrasi. nal dalam pelaksanaanya karena masih adanya kemacetan dan tindakan tidak disiplin dari para pengemudi angkutan umum seperti mengetem kendaraan di sembarang tempat dan menaikan atau menurunkan penumpang di sembarang tempat bahkan di tengah jalan.

Tabel. 5

Rekapitulasi untuk variabel Disiplin

\begin{tabular}{clc}
\hline NO & \multicolumn{1}{c}{ Dimensi } & $\begin{array}{c}\text { Rata-rata } \\
\text { skor }\end{array}$ \\
\hline 1. & Tujuan Disiplin Kerja & $\mathbf{3 , 3 5}$ \\
2. & $\begin{array}{l}\text { Faktor Pendukung } \\
\text { Disiplin Kerja }\end{array}$ & $\mathbf{3 , 1 6}$ \\
3. & $\begin{array}{l}\text { Faktor Penentu } \\
\text { Disiplin Kerja } \\
\text { Rata-rata skor }\end{array}$ & $\mathbf{3 , 3 8}$ \\
& $\mathbf{3 , 2 9}$ \\
\hline
\end{tabular}

Berdasarkan tabel di atas diketahui rata-rata skor untuk variabel disiplin adalah sebesar 3,29 dengan interpretasi Tinggi. Artinya, penilaian responden tentang dimensi tujuan disiplin kerja, faktor pendukung disiplin kerja, serta faktor penentu disiplin kerja secara garis besar adalah cukup baik. Hal ini tersebut menunjukan disiplin pengemudi angkutan umum sudah cukup baik, artinya secara kualitas pengemudi sudah dinilai cukup baik, hanya belum optimal karena masih 
ada pengemudi angkutan umum yang tidak disiplin karena masih adanya pengemudi yang tidak mengindahkan rambu-rambu lintas seperti berhenti di sembarang tempat, mengetem, menurunkan dan menaikan penumpang disembarang tempat bahkan di tengah jalan sehingga menyebabkan kemacetan lalu lintas.

\section{KESIMPULAN DAN IMPLIKASI \\ Kesimpulan}

Berdasarkan

pembahasan

mengenai Pengaruh Pengawasan DLLAJ Terhadap Kedisiplinan Pengemudi Angkutan Umum di Kota Bogor, maka dapat di ambil kesimpulan sebagai berikut :

1. Pengawasan sarana prasarana lalu lintas pada dasarnya telah dilaksanakan dengan cukup, hal tersebut ditunjukkan oleh hasil jawaban responden dan wawancara dengan petugas pengawasan DLLAJ dengan interprestasi Cukup dari empat dimensi variabel pengawasan.

2. Disiplin pengemudi angkutan umum di Kota Bogor pada umumnya mendapatkan interprestasi cukup dari jawaban responden, tapi hal ini belum sepenuhnya optimal karena banyak pengemudi angkutan umum yang masih mengetem sembarangan dan menurunkan penumpang bukan pada tempatnya.

\section{DAFTAR PUSTAKA}

Handoko, T. Hani. 2012. Manajemen Edisi 2. Yogyakarta: BPFE Yogyakarta.

Handoko, T. Hani. 2012. Manajemen Personalia dan Sumber Daya Manusia. Yogyakarta: BPFE Yogyakarta.

Hasibuan. S. P. Malayu. 2007. Manajemen Sumber Daya Manusia. Jakarta: Bumi Aksara.

Manullang, M. 2001. Dasar-Dasar Manajemen. Yogyakarta: Gadjah Mada University Press.
Sugiyono. 2009. Metode Penelitian Kuantitatif Kualitatif dan $R \& D$. Bandung: Alfabeta.

Sunarti, Euis. 2004. Mengasuh Dengan Hati. Jakarta: Gramedia.

\section{DAFTAR DOKUMEN}

Undang - Undang Republik Indonesia Nomor 22 Tahun 2009 Tentang Lalu Lintas dan Angkutan Jalan 
Pengaruh Pengawasan Dinas LLAJ Terhadap Kedisiplinan Pengemudi Angkutan Umum di Kota

Bogor 